\title{
Relatos de los niños desde una perspectiva de memoria reconstructiva
}

\section{Children's narratives from a reconstructive memory perspective}

Fecha recepción: 30 de mayo de 2021 / fecha aceptación: 29 de junio de 2021

\author{
María Teresa del Río Albornoz ${ }^{1}$ \\ María Elisa Molina Pavez ${ }^{2}$
}

\begin{abstract}
Resumen
Este artículo analiza la controversia entre posturas teóricas sobre memoria, denominadas recuperativa y reconstructiva, rescatando las ideas de Mead, Bergson (1959) y Bartlett (1932), particularmente en lo relativo a la teorización acerca de la noción de tiempo, la cual debe ser reconsiderada a la hora de analizar el concepto de veracidad y validez de los recuerdos. Se usa como ejemplo de análisis las consideraciones sobre la credibilidad de los relatos de niños en el campo del abuso infantil.
\end{abstract}

Palabras claves: memoria reconstructiva, temporalidad, relatos, abuso infantil.

1 Doctora en Psicología- Pontificia Universidad Católica de Chile. Académica planta, Escuela de Psicología y Terapia Ocupacional, Universidad Central de Chile.

Correo electrónico: mdelrioa@ucentral.cl

2 Doctora PhD en Psicología - Pontificia Universidad Católica de Chile. Académica - Directora de Unidad de investigación en Procesos Relacionales y Directora área clínica - Facultad de Psicología - Universidad del Desarrollo - Chile. Correo electrónico: memolina@udd.cl. ORCID: https://orcid.org/0000-0003-0619-9607 


\begin{abstract}
This article analyses the controversy among theoretical positions on memory, called recuperative and reconstructive, rescuing the ideas of Mead, Bergson (1959) and Bartlett (1932), particularly related to the theorization on the notion of time, which should be reconsidered in the light of the concept of veracity and validity of memories. Considerations on the credibility of children's narratives in the field of child abuse are used as ground of analysis.
\end{abstract}

Keywords: memory reconstructive, temporality, narratives, child abuse.

\title{
Introducción
}

Durante los últimos años, el desarrollo que ha tenido el abordaje de casos de abusos a menores ha resultado en la asignación de un rol cada vez más relevante al relato de los niños de sus propias experiencias. Particularmente en el contexto judicial, sus narraciones pueden orientar las decisiones en cuanto a considerar si un hecho ha ocurrido o no y si es considerado como irrefutable. En este contexto surge la necesidad de establecer criterios respecto de la veracidad de los recuerdos infantiles, lo que ha generado gran controversia (Fivush, 1994; De Paul y Arruabarrena,1994; Cortés y Cantón, 2000; Fisher y Whiting, 2002; Ceci y Bruck, 2003; Medina et al., 2014) poniendo en la agenda una vez más el debate que hay en psicología sobre la memoria. Sin embargo, muchos autores más que poner realmente el debate sobre la memoria -a través de su evocación por medio del relato- en el tapete, intentan sortear un tema resbaladizo en el que hay grandes avances, pero no existe consenso. Se intenta abordar un proceso mental altamente complejo y, en el caso de los niños, cruzado por el desarrollo evolutivo, lo que complejiza aún más los criterios.

En la Guía de Entrevistas Investigativa con Niños, Niñas y Adolescentes Víctimas de Delitos Sexuales (2012) del Ministerio Público de Chile se enfatiza:

"Es importante tener presente que los niños podrían no relatar todos los detalles del delito, pudiendo minimizar o retener información, ya sea porque no están motivados a entregarla, porque no están preparados para hacerlo, o bien porque no comprenden la naturaleza de la diligencia o no conocen la importancia que esto reviste. De hecho, los niños/as son más proclives a negar experiencias 
que efectivamente hayan vivido como traumáticas, que a realizar denuncias sobre un hecho falso".

En la Guía para la Evaluación Pericial de Testimonio en Víctimas de Delitos Sexuales (2019), del Ministerio Público de Chile, se reconoce la importancia de los relatos afirmando:

"Pero este cuestionamiento no se queda allí y trasciende también al cuestionamiento de los niños como testigos fiables, aduciendo a los procesos de memoria y sus limitaciones, a las limitaciones en su narrativa, que les dificultan comunicar sus vivencias con precisión y en detalle, unidas a una supuesta tendencia a la sugestibilidad y problemas, en algunas edades, para distinguir la fantasía de la realidad, elementos todos que han contribuido a generar dudas respecto de la credibilidad de estos testigos invalidando sus reportes, tanto en los juicios como fuera de estos (Huerta y Muñoz, 2015)".

Esta completa guía incluye en su análisis aspectos personales y aspectos situacionales (p. 227) que darían cuenta de la variabilidad de la expresión de los recuerdos y complejizan cualquier examen sobre credibilidad de un niño en particular. Se busca un relato veraz y coherente, aunque se reconoce la gran dificultad para obtenerlo.

Llama la atención que la definición de memoria que adhiere a una particular perspectiva no parece ser particularmente relevante cuando se revisan protocolos, guías u otra literatura sobre análisis de relato de los niños, no apareciendo en la discusión o teniendo escasa importancia.

Excepción sería la memoria traumática, campo fértil de investigación que ha brindado mucho conocimiento desde la psicología clínica y que reconoce el impacto sobre la particular expresión psicológica de cada sujeto como parte integral de su expresión e influencia en los procesos cognitivos, propiciando, por ejemplo, fragmentación de los relatos o lagunas de memoria.

También, a modo de ejemplo, Köhnken y colegas (2015) en su excelente artículo sobre la validez de los relatos de los niños (SVA) argumentan:

“Tal como lo planteara Loftus (1996), cada vez que recordamos la huella de la memoria que lo representa se reconstruye, lo que implica que con cada recuperación los recuerdos se van transformando 
mediante la incorporación de nuevos datos y la reinterpretación de los ya existentes. Cuanto más tiempo ha transcurrido y cuantas más personas han intervenido con preguntas, más veces se ha tenido que reconstruir el hecho, más información se habrá distorsionado y más se habrá modificado, también, la manera como expresan los sujetos esa información".

Pareciera que se privilegia una definición de memoria recuperativa siendo esta la más fiable, aunque se reconoce que funciona en forma reconstructiva constituyendo esta cualidad un problema para la credibilidad del relato y que, por lo tanto, debería ser contrarrestada. Lo que aparece claramente explicitado y estudiado es la inmensa dificultad para obtener relatos creíbles de niños más allá de toda duda razonable.

Otra aproximación es la evaluación y análisis fenomenológico del relato en pericias realizadas por abuso sexual en niños/as-adolescentes (Gil et al., 2011; Quiroga et al., 2010).

Allí se argumenta que, además del análisis de contenido (CBCA), se debe incluir un análisis de la narración de la víctima que incluya aspectos propios de sus vivencias e interpretación de los hechos, aludiendo a las particulares significaciones y vivencias que cada niño trae consigo. Los autores reclaman que la evaluación pericial no incluye significativamente este aspecto, tomando la expresión idiosincrático del relato y el contexto en que se despliega más bien como un factor a controlar y no como característica insoslayable.

Medina et al. (2014) refieren que la credibilidad de los niños entrevistados por sospecha de abuso debería alcanzarse a través de un proceso diagnóstico que resulte de una valoración multidisciplinar en que se incluyan examen médico forense, examen psicológico forense y valoración social. Añaden que el diagnóstico pericial de los abusos sexuales a menores sería aún un desafío y la validez del informe sobre la credibilidad de las declaraciones requiere experiencia del profesional y solidez en los argumentos en los que se basan las conclusiones que deben provenir de varias fuentes, concluyendo que el SVA no constituye un elemento objetivo, único y concluyente en los casos de abusos sexuales a menores (p.77).

Escapa a la intención de las autoras hacer una revisión exhaustiva de la literatura sobre protocolos y criterios de veracidad. Aquí se tomarán 
lineamientos centrales para poner en tensión el concepto de memoria que subyace a los relatos de los niños.

Los problemas que se generan en el campo de la narración de los niños de sus experiencias atañen de manera importante al concepto de memoria que está a la base de las distintas posturas teóricas, demarcando los límites de lo esperable en la manifestación de este fenómeno. Algunas líneas de investigación consideran que los niños tienen memorias frágiles, abiertas a la confusión y a la sugestión (Ceci y Bruck, 1993; Schooler, 1994; Terr, 1994; Ornstein et al., 1998; Ceci y Hembrooke, 2001). Estas ideas surgen de distintas vertientes. Una de ellas es la evidencia de que no se tienen recuerdos acerca de las experiencias antes de los tres años de vida. La segunda vertiente proviene de las investigaciones en torno a la sugestión afirmando que mientras menor es un niño, más propenso es a ella, lo que lo llevaría a crear, bajo el influjo de otra persona, acontecimientos que no han ocurrido. La tercera vertiente que hace subestimar los relatos de niños pequeños es la creencia en que ellos confunden fantasía y realidad. A partir de estos supuestos, los dichos de los niños carecerían de legitimidad como testimonios de hechos reales. Sin embargo, también se han reportado evidencias a favor de la capacidad de los niños de recordar eventos del pasado y por períodos bastante prolongados de tiempo, enfatizando factores que pueden facilitar o dificultar la veracidad de sus relatos (Nelson, 1988; Fivush, 1994; Bauer, 1996).

Siguiendo a Echeburúa y colaboradores, entre un relato creíble y un relato veraz cabe hacer una distinción. La credibilidad es considerada como producto de una integración de las respuestas emocionales, cognitivas y conductuales del menor que son comprensibles y que están en consonancia con el relato expresado, mientras que un testimonio es veraz o válido solo cuando el recuerdo representa de una forma correcta y adecuada la realidad ocurrida (Echeburúa et al., 1998).

Las controversias planteadas por estas vertientes acerca de la legitimidad de los relatos de los niños, parecen compartir la visión acerca de los recuerdos como eventos relativamente estáticos que no sufrirían o no debieran sufrir modificaciones en el tiempo y en las subsecuentes operaciones de la memoria. Para que un relato sea verdadero, desde esta perspectiva, una acción de recuerdo debería reproducir lo más exactamente posible el evento original al que alude, de acuerdo con sus características unitarias y relativamente fijas. Llamamos a este supuesto 'memoria 
recuperativa' desde el cual podemos hacer distinciones entre recuerdos más o menos exactos, distorsiones, relato verdadero y relato falso. Otra noción que parecen compartir los enfoques mencionados es la veracidad ligada a una experiencia individual e intrapsíquica de los fenómenos a recordar, que pueden ser distorsionados cuando se entra en relación con otros. No solo se considera al evento como unitario, el proceso cognitivo implicado también lo es.

Una perspectiva diferente a lo considerado anteriormente proviene de la tradición de memoria reconstructiva que alude a una permanente transformación del evento recordado, que se pone en juego en el contexto social de las interacciones con los otros y con la cultura. En este contexto se necesita otro lenguaje para referirse a la veracidad, distinto al concepto de exactitud de los recuerdos, el cual aquí no parece aplicable. Aludiendo a la condición reconstructiva de la memoria, Mead (2002) señala:

El pasado es una construcción de tal naturaleza que la referencia que se encuentra en este no es sobre eventos que tengan una realidad independiente del presente en el cual tiene su asiento la realidad, sino más bien es una interpretación del presente en su condición de pasaje lo que permite a la conducta inteligente proseguir (2002, p.57).

De este párrafo se pueden extraer algunas ideas centrales al tema de la memoria. En primer lugar, la persona como protagonista está siempre situada desde un momento presente, y solo desde este puede acceder a interpretar los eventos del pasado. El presente es esencialmente un pasaje temporal y transitorio, lo que sitúa a la persona continuamente en un nuevo escenario para la elaboración de la experiencia. Así, el pasado que emerge en el momento presente no puede ser considerado como evento único, sino que también como un proceso en transformación. Además, cuando Mead habla de proseguir, se refiere a la orientación de la conducta hacia el futuro inmediato, cuyas acciones estarán determinadas por el significado de quien elabora psicológicamente en el momento presente. En consecuencia, pasado, presente y futuro se entrelazan en la vivencia de la realidad. Se cuestiona, entonces, la noción de versiones únicas acerca del pasado, pero a la vez la idea de que puede surgir y ser válida cualquier versión o elaboración de la realidad en el momento presente, ya que hay una relación pasado, presente y futuro inmediato que no es posible obviar debido a que existe una conexión que no es arbitraria. 
Otro aspecto importante para la discusión teórica es la noción de origen sociocultural de la mente propia de la memoria reconstructiva, lo cual no es sustentado por quienes proponen el concepto reproductivo de memoria, aludiendo más bien a un enfoque intrapsíquico e individual. Subyace a la noción sociocultural de la mente (cf. Valsiner y van der Veer, 2000) una construcción continua de la experiencia a través de la mediación de procesos de significado con múltiples interlocutores tanto desde la vertiente subjetiva como socio-cultural.

\section{Distinciones sobre la memoria}

Dada la variabilidad e impredictibilidad de la conducta humana cabe preguntarse cómo se procesan los eventos del pasado, lo que ha llevado a los investigadores a considerar diferentes perspectivas teóricas para explicar y comprender dicho fenómeno. Están por una parte las teorías del rastro, según las cuales la memoria opera a través mecanismos de registro de la experiencia, que posteriormente es recuperada, por la conexión con algún rastro fisiológicamente identificable, resultando en una versión única y exacta del evento original. La calidad del recuerdo y la noción de veracidad y validez van a depender del grado en que la recuperación concuerda con el evento original dependiendo si los 'rastros' o 'huellas' o si los procesos de monitoreo de los registros son firmes o débiles. (Bursen, 1978; Ornstein, Ceci, y Loftus, 1998; Ceci y Brucks 1993). Desde esta concepción los niños tendrían que recordar los eventos con alto detalle y especificidad, no siendo constructores ni elaboradores de su experiencia sino reproductores más bien pasivos que registran, copian y evocan en forma exacta un evento. Desde esta perspectiva quienes son considerados con dificultades a la hora de 'recuperar' un evento del pasado, tendrían una memoria frágil y defectuosa.

Una conceptualización que ofrece ampliar las posibilidades respecto de la teoría del rastro para estudiar este fenómeno en niños pequeños propone que la memoria opera a partir de esquemas generales o rutinas de acciones ordenadas en secuencias temporales. Para referirse a este tipo de funcionamiento cognitivo distintos autores señalan conceptos tales como guiones (Ceci y Bruck, 1993), memoria de evento genérico (Nelson, 1993) o relación habilitadora entre acciones (Bauer, 1996). Estas propuestas hacen referencia a un tipo de memoria que funciona como esquema o acciones coordinadas, como una estructura de acciones que conforman un todo, donde una acción es al mismo tiempo previa y necesaria para una acción subsiguiente en función 
de una meta determinada. Por ejemplo, si queremos preparar una receta de comida tendremos que reunir los ingredientes y seguir una secuencia de acciones para un resultado exitoso. Desde este enfoque mientras más rico es un guion, más accesible es al recuerdo. Quienes han realizado investigación desde este marco conceptual proponen que la memoria en niños pequeños se comporta de esta forma, lo que permite explicar tanto la recuperación de experiencias vividas como la distorsión de las características y contenidos de los relatos. Tanto los modelos de rastro como de esquemas de acciones son propuestos desde un concepto individual e intrapsíquico de mente.

Un modelo que reconoce el fenómeno de la memoria como una dinámica sociocultural en la cual los recuerdos son co-construidos a través del discurso social, es el de memoria autobiográfica: este tipo de memoria descrita por Nelson (1983) intervendría en la elaboración del sentido de sí mismo y de la propia historia de vida y se desarrollaría a partir del término de la amnesia infantil. La autora hipotetiza un efecto de este tipo de memoria en la amnesia de los primeros años de la infancia, generándose una especie de primacía de los relatos autobiográficos, quedando lo que no forma parte de estas nuevas narrativas fuera de las funciones conscientes.

La memoria autobiográfica es social en su origen y depende en gran medida de la interacción lingüística con otros, de ahí su carácter narrativo. La memoria autobiográfica se favorecería cuando la madre (o los adultos que rodean al niño) es activa y dialoga con el niño acerca de sus recuerdos en términos narrativos, haciéndole preguntas como qué pasó, cuándo, dónde y con quién, favoreciendo el desarrollo de procesos cognitivos asociados a la memoria. Esta forma elaborativa y activa del sujeto proporcionaría bases para la construcción de historias y relatos ricos en contenidos y relaciones. Se ha demostrado que la capacidad de recuerdo aumenta en los niños que tienen este tipo de apoyo de sus madres en comparación con los que han recibido una interacción con un estilo más pragmático y menos dialógico (Nelson, 1993, 2002). Si se consideran estas observaciones desde una perspectiva intrapsíquica e individual se abre la posibilidad que los niños sean influidos por contenidos introducidos por terceros en el proceso de la interacción social, distorsionando sus recuerdos y alterando las cualidades de los reportes de eventos del pasado.

Otro campo que ha tenido especial consideración en la discusión sobre la veracidad de los relatos de los niños es el estudio de la sugestibilidad 
entendida como un tipo de mecanismo psicológico que afectaría la calidad y cualidad de los relatos.

Ceci y Bruck (2003) entienden este concepto como: "el grado en el cual las codificaciones, registros, recuperación y reporte que hacen los niños de los eventos, puede ser influenciado por un rango de factores sociales y psicológicos" (p. 404). Los estudios han demostrado diferencias por edad asociadas a la sugestibilidad y otros factores que darían cuenta de la propensión y capacidad de resistirse a este mecanismo, tanto en niños como adultos. Según la teoría del rastro, el efecto de la sugestión sobre la memoria se produciría por fallas de 'almacenamiento' o anomalías en la recuperación, que resultarían en una alteración de los rasgos del evento original.

Ceci y Bruck (1993, 2003), aludiendo al concepto de secuencias estructuradas de acción, señalan que la sugestibilidad opera cuando existen conexiones no especificadas entre acciones, induciendo aspectos 'que no han ocurrido' a ser incluidos o calzados en un guion. Según estos autores, los niños pequeños serían más susceptibles de sufrir distorsiones en sus recuerdos, por la permeabilidad de estos a contenidos que no concuerdan, ya que un contenido no concordante con el guion se convierte en parte de este. Por ejemplo, el abuso como parte del ritual de limpieza o de juego. En la medida que hay demasiada novedad o discrepancia, aumenta la probabilidad que el niño se sienta incómodo, ansioso y busque evitar el enfrentamiento con la nueva situación. Una forma de superar este impasse, sería que el niño incorporara a su guion lo discrepante, que en este caso es la introducción de una conducta de abuso en la rutina de aseo, a través de la sugestión de que se trata de una modalidad distinta de limpieza, que la incorpora a la categoría de 'hora del baño' y transforma la definición de esa conducta en particular. Cabe preguntarse cuáles son los fenómenos implicados en este simple ejemplo. Hay un acto de recuerdo y hay diferentes interpretaciones de la experiencia. Algunos considerarían que ocurre una distorsión del evento pasado y una evocación inexacta de los hechos, mientras que otros dirían que se trata de una interpretación posible para el niño de un evento pasado.

Los enfoques narrativos de la memoria han explicado el fenómeno de sugestibilidad a partir de estrategias para rellenar brechas y distorsiones del evento original. Es decir, en el proceso de construcción de la experiencia se van clarificando vaguedades de los relatos, resolviendo contradicciones 
y rellenando vacíos. Al hablar de vaguedades, contradicciones o vacíos se presupone una coherencia óptima entre eventos recordados que perdura a pesar del tiempo transcurrido. A modo de ejemplo, existe una demanda del mundo institucional y social a dar coherencia a los relatos (Coulborn Faller, 1988; Canton y Cortés, 2000; Jones, 1992). Desde esta perspectiva, la coherencia no sería un criterio de la veracidad de los relatos.

Desde la perspectiva de las teorías de esquemas de acciones y narrativa surge la necesidad de explicar la fragilidad y baja confiabilidad de la memoria infantil y de identificar las condiciones bajo las cuales se puede obtener precisión en los reportes, a partir del criterio que los eventos pertenecientes al pasado no se modifican y que la memoria opera en el mundo privado de la experiencia psíquica. Así, se constituye un escenario que presenta pocas alternativas, el cual se refiere a la indeterminación de los relatos de los niños, especialmente cuando se determinan criterios de veracidad basados en precisión y privacidad.

Estas concepciones teóricas apuntan de un modo otro a procesos de registro y recuperación de contenidos de carácter episódico, en la teoría de rastros, de carácter procedural, en los esquemas coordinados de acción y de carácter declarativo en los enfoques narrativos, compartiendo supuestos similares de veracidad. Aún cuando el enfoque narrativo reconoce en mayor grado que otros el rol activo de la persona en el proceso de memoria, todas estas teorías tienen a la base una concepción temporal de pasado fijo que no cambia.

\section{La dimensión sociocultural: ¿es distorsionante del recuerdo?}

Si no se tolera una concepción de aproximaciones gruesas de la memoria, se llega a la necesidad de explorar acerca de las causas de las 'distorsiones' cuando el evento no es evocado en forma exacta. Tal es la situación al plantear los factores socio culturales como fenómenos que pueden tener efectos emocionales en los niños e inducir información errónea acerca de los acontecimientos del pasado. Entre estos factores se consideran, entre otros, aspectos relacionales como es el caso de las entrevistas con personas percibidas como autoridad, o con aquellas que se muestran amables y que despiertan confianza, o el caso de interrogatorios insistentes, repetitivos y, por último, la tendencia de los niños a complacer al entrevistador (Coulborn Faller, 1988; Jones, 1992; Canton y Cortés, 2000; Ceci y Bruck, 2003). 
En esta misma línea ha habido estudios que se han abocado a explorar los factores que favorecen la obtención de relatos lo más veraces posibles. Cuando el tema sobre el cual un niño construye un relato apunta a una acción central del evento original, o el niño ha sido un participante activo de la acción que está evocando, o la acción ha involucrado su propio cuerpo y el relato surge de una narración libre, las probabilidades de que se trate de un relato veraz aumentan, considerándose como factores de resistencia a la sugestión (Bauer, 1996). A partir de estos criterios, la precisión de los reportes pone el énfasis en la naturaleza idiosincrática de estos. Terr (1996), estudiando los efectos de experiencias traumáticas en niños, señala que aun cuando se producen distorsiones de los recuerdos que apuntan a defectos sobre la memoria producidos por tales experiencias, estas no anulan las capacidades de una persona o un niño para entregar testimonios veraces de eventos vividos, porque recuerdan aspectos centrales, momentos particulares en la secuencia del evento, lugares particulares, claves de memorias no verbales como juegos, cambios de personalidad, miedos relacionados con el trauma. Estos criterios orientan las entrevistas destinadas a obtener relatos de las experiencias infantiles.

El contexto en que el niño está inmerso y el constante intercambio que tiene con este, los procesos compartidos, interaccionales, dialógicos y culturales, desde las concepciones recuperativas de la memoria, son considerados como aspectos que pueden distorsionar o facilitar el recuerdo. La interpretación y re-significación de los acontecimientos de vida, en que se producen diferentes grados de influencia de los otros, son vistos como perturbadores de los procesos cognitivos de la memoria y no como constitutivos de ella.

Quienes sostienen una perspectiva narrativa, aun cuando reconocen que este proceso se lleva a cabo a través de actividades compartidas, destacando su carácter eminentemente social, tratan el tema de la veracidad asociándola a la precisión de los recuerdos. En este marco, la validez dependería de la alusión directa por el recuerdo al evento al que apunta en el pasado versus lo mediado que esté por diálogos con otros. Se asume, desde esta perspectiva, que el contexto socio-cultural puede o favorecer los recuerdos o distorsionarlos (Nelson, 1993; Fivush, 1994;). Bajo estos supuestos, se impone una restricción a la veracidad que es la naturaleza individual e intrapsíquica del acto de recordar. 
Se hace evidente que lo que ocurre entre un evento original y el momento en que este es evocado, lo que puede ser señalado como mediación temporal y su participación en los actos de recuerdo, no son considerados por los estudios y modelos teóricos a los que se ha hecho referencia. Los enfoques narrativos, aun cuando sostienen que los recuerdos son construidos y transformados a través de las conversaciones con otros en un proceso gradual (Fivush, 1994), al igual que las teorías del rastro y de esquemas de acción, dejan fuera estos procesos de fenómeno de la memoria, suponiendo que para la recuperación se realiza una especie de salto hacia un punto fijo del pasado donde las características del evento de ese pasado continúan idénticas a como este fue vivido.

Entonces, ¿qué es lo que podemos esperar del pasado? ¿Cuáles son los aspectos del pasado que pueden prevalecer? ¿Cómo se expresa el pasado en el presente?

\section{Memoria reconstructiva}

Apoyándose en los fundamentos teóricos que sostienen la noción de memoria reconstructiva, se puede cuestionar la idea de recuperar desde el presente lo que quedó almacenado como evento original en un instante único en el pasado, con el objetivo de calzar los contenidos de ambos momentos en el tiempo. Desde esta nueva perspectiva existirían otros criterios para determinar la validez de los recuerdos, en los cuales la reflexión sobre las nociones de temporalidad y de hacer sentido de la experiencia tendrían un rol central.

Bartlett (1932) conceptualiza la memoria como un proceso, una cronología y no como almacén de contenidos. Él utiliza el concepto de esquema para referirse a una disposición procedural que se actualiza y realiza momento a momento proponiendo, en lugar de instantes que se conectan y contenidos que se guardan y se mantienen, 'transiciones' de reacciones pasadas a reacciones futuras en un proceso continuo que elige la acción siguiente como una forma de armar una totalidad. Esta concepción de esquema difiere de los esquemas como guiones o asociaciones entre acciones, respecto a la manera en como trata la noción de tiempo. El concepto de esquema de acción pone el acento en las características estructurales de las acciones (Ceci y Bruck, 1993; Bauer, 1996; Nelson, 1993), las cuales se dan en un tiempo, son atravesadas por un momento de tiempo, pero no ocurren 'con' 
el tiempo, durante el tiempo, como es la manera en que Bartlett concibe los esquemas. Desde esta nueva perspectiva, no podemos considerar instantes que se conectan, sino un proceso en transcurso. La idea de formar una totalidad se relaciona con los esquemas en cuanto a tendencias del organismo a completar patrones. Así, se genera la percepción de continuidad de la experiencia, a partir de la cual la persona construye una noción de identidad y de sentido. Esta noción de proceso en transcurso también es aludida por Bergson (1959) a través de su concepto de duración como un flujo que es transcurso, que tiene una identidad indivisible y, al mismo tiempo, marca una diferencia entre el pasado y el presente. Así, completar una totalidad en Bartlett e indivisibilidad en Bergson, aparecen como conceptos que contribuyen a posicionarse teóricamente en torno a la noción de hacer sentido de la experiencia. Aquí hacer sentido está asociado estrechamente a temporalidad.

De acuerdo con Bergson, la memoria sigue una operación cognitiva desde la ocurrencia de un evento a su eventual evocación en un momento presente. El pasado se hace presente y, en el acto de presentarse, aparece congruente a nuestro discernir sobre lo que nos aconteció. El autor opone la concepción de memoria a las leyes de la causalidad y de la conciencia como mecanismo radical que enlaza todos los fenómenos. No es el pasado que será nuevamente evocado en un momento presente y nuevamente evocado repetidamente. La memoria es un rodeo que difiere o dilata la acción, abriendo un espacio de virtualidad para acceder al pasado y convertirlo en capacidad de actuar. Para comprender mejor la unidad entre pasado y futuro en el presente, pueden ayudar las palabras de Bergson:

"Llega un momento en que el recuerdo así reducido se engasta tan bien en la percepción presente que no sabríamos decir donde termina la percepción y donde comienza el recuerdo" (p. 301).

Por engaste, Berson hace referencia a que pasado y presente se conectan, aunque no de manera causal o necesaria, produciéndose una completación de la experiencia en el presente, lo que es contingente y, por lo tanto, no se puede separar del momento en el cual se da la operación. Es decir, la temporalidad imprime una particularidad a cada experiencia de recuerdo que hace a cada momento único e irrepetible. Esta originalidad de la experiencia se explica porque la memoria, como fenómeno del presente, genera procesos que van del objeto percibido a las evocaciones y de estas al objeto, transformándose unos y otros incesantemente, creando nuevamente al objeto en 
una acción que abarca aspectos que se van relacionando a la experiencia de continuidad. En sus palabras:

"Se ve que el progreso de la atención tiene por efecto crear de nuevo, no solamente el objeto percibido, sino los sistemas cada vez más amplios a los que puede referirse" (Bergson, 1959 p. 300).

Con esto, el autor alude a los procesos de significación asociados a esta construcción. A través de este proceso que Bergson llama "circuito cerrado" de la memoria, contribuye a profundizar en la noción de formar una totalidad. La totalidad se va conformando a partir de las características del objeto percibido, los detalles concomitantes o aspectos 'virtuales' que son tomados del pasado y el sistema que va surgiendo como resultado de la construcción.

Por otra parte, en el análisis del proceso mismo del recuerdo se pueden distinguir diferentes momentos que contribuyen a la reflexión en torno a la validez de los relatos del pasado. Los esquemas estudiados por Bartlett (1932) corresponderían a la forma más básica ejerciendo cierta determinación sobre la acción. Él distingue una forma más compleja de memoria que estaría dada por las imágenes, a través de las cuales se realizarían operaciones distantes en el tiempo para contactar eventos del pasado. La función imagen rompe la rigidez e inmediatez de los esquemas dando al organismo la capacidad para, a través de las imágenes, referirse a operaciones distantes en el tiempo y articular o integrar tendencias en conflicto. Las imágenes son de naturaleza concreta -tienen estructura- y multidimensional, que es lo que permite que múltiples tendencias en conflicto se satisfagan en una misma imagen. Esto es lo que da variabilidad a la imagen y, desde ella, al recuerdo, permitiendo múltiples interpretaciones de la experiencia al abordarla desde sus diferentes ángulos. Se puede recordar un evento singular y, al mismo tiempo, dar relatos diferentes porque se recuerda a través de una imagen. Un tercer momento descrito por Bartlett es cuando se integran el esquema y la imagen en un proceso de re-construcción para estructurar una narración. Los tres fenómenos conforman el proceso de memoria, pero es el tercero el más característico como fenómeno propiamente humano, el cual, sin embargo, es tratado como elemento distorsionador por los teóricos de la noción recuperativa.

Respecto a la noción de temporalidad, la conceptualización de Mead complementa los postulados de Bartlett y Bergson. Él propone la noción 
de pasaje en la experiencia de la temporalidad, en el cual el presente es el tránsito donde se encuentran pasado y futuro, lo que se manifiesta en la forma de un 'emergente'. El principio básico que subyacería al concepto de pasaje es la posibilidad de la mente de pasar de una actitud a otra con la consecuente pertenencia a ambas; dicho de otro modo, es el presente que tiene la característica de pertenecer a diferentes sistemas en su pasaje de lo viejo a lo nuevo (Mead, p. 87). Esta capacidad de la mente permite a la persona responder al entorno desde diferentes actitudes o perspectivas. En este pasaje, el pasado que es parte del presente es el aspecto menos evidente de la experiencia presente y, sin embargo, tiene un carácter irrevocable. La noción de irrevocabilidad remite al aspecto no flexible del recuerdo y de cada presente, su referencia a un pasado que, siendo parte del presente, es oscuro al presente y está fuera de nuestras manos. El pasado es irrecuperable, pero además el proceso de vida, en cuanto pasaje, no tiene marcha atrás, tiene lugar en una dirección temporal inalterable, por lo cual el pasado es evocado desde la emergencia de un presente siempre nuevo.

Cabe preguntarse cómo opera el pasado en el relato producido por un niño y, junto con ello, si podemos acceder a una pretensión de veracidad o coherencia con este. No existiría, en palabras de Mead, un presente independiente del pasado y, a la vez, no es pensable lo que él llama un relato certero de un evento pasado en sí mismo. Tampoco podemos representarnos el pasado en su totalidad, ya que es irrecuperable como aspecto más básico de la irrevocabilidad. Conviene distinguir que irrevocabilidad en este contexto alude al impacto que permanentemente producen las experiencias del pasado en el presente, un impacto que está mediado por múltiples procesos en el aquí y ahora. Todo acto humano está implicado en este fenómeno, desde cómo hacemos ciencia hasta los actos cotidianos. Vivimos en un mundo reconstruido.

Esto implica a su vez que el evento pasado permanece, aun si no tenemos certeza sobre cómo fue un evento en particular. Lo que ha pasado, ha pasado. Esta unidad de presente, pasado y futuro se asemeja a un juego de poleas que está en permanente movimiento y que, en la medida en que una se mueve (el presente que avanza hacia el futuro), también se mueven las otras que son los eventos del pasado que continúan su proceso de transformación con el transcurrir de la experiencia presente y el futuro inmediato que se transforma como posibilidad nueva. Entonces la irrevocabilidad del pasado continúa participando en un proceso de redefinición y transformación 
a modo de pirámide invertida en cuyo vértice existe un acontecimiento que continuará conectándose con nuevas experiencias, diálogos, conceptos, documentos, monumentos, siempre en un flujo de cambio hacia el futuro. Así, la reconstrucción del pasado no completa nunca su finalidad, siempre está sujeta a reformulación donde "la novedad de cada futuro demanda un pasado novedoso" (Mead, 1932, p. 59).

Los conceptos mencionados plantean un escenario para la elaboración de la experiencia donde la variabilidad tiene un lugar en los fenómenos asociados al recuerdo de un evento y los comportamientos resultantes. Así, es inevitable la novedad en cada nuevo recuerdo, en cada encuentro con un interlocutor diferente y cada contexto en que se entrega un relato del pasado. También son parte de la memoria la edad del niño, su estado emocional y la actividad que realiza mientras cuenta, si pinta, dibuja o juega, los que son aspectos constitutivos del fenómeno emergente, pero considerados como factores distorsionadores de la memoria, desde otras concepciones (Terr, 1996; Bauer, 1996; Ceci, S. J. y Hembrook, H., 2002; Ceci y Bruck, 2003). En este nuevo marco conceptual, las contradicciones, vaguedades, vacíos de los relatos y los mecanismos a través de los cuales estos son resueltos en la narración, no son atribuidos a déficits de la persona o de sus procesos cognitivos, sino que forman parte de la memoria como procesos personales y sociales en un contexto temporal y espacial (Mead en Valsiner, 2000). Según Mead, el carácter reconstructivo de la memoria es esencial en la conducta de un ser inteligente en el universo.

Estos planteamientos, sin embargo, no apoyan la idea de que cualquier relato vale, ya que continuidad (Bartlett), indivisibilidad (Bergson) e irrevocabilidad (Mead) son cualidades inherentes de la experiencia, a partir de las cuales se establece un rango de flexibilidad y de restricción que puede orientar la determinación de un acto o una narración como válida o no.

Por otra parte, esta coherencia del recuerdo no solo es referida a procesos individuales y subjetivos de quien participa en primera persona en un acto mnémico, como lo sostiene la postura recuperativa de la memoria, sino también a procesos sociales y de la cultura que tienen una participación en el desarrollo del proceso re-constructivo. En una concepción social de la mente, la memoria no se sitúa dentro de la cabeza, sino que es un proceso que hace uso de medios personales, subjetivos o internos, intersubjetivos y también culturales. Así, el hecho de que el niño evoque relatos en una interlocución no se considera erróneo desde esta postura, ya que los diálogos son 
parte de la memoria, abordándose su experiencia no como un montón de situaciones aisladas, sino como un tejido que toma diferentes expresiones tanto de su mundo individual privado como de su contexto social y cultural.

En este artículo se sostiene que el concepto de hacer sentido de la experiencia puede orientar hacia una nueva teorización acerca de la veracidad. Hacer sentido por una parte ya ha sido asociado al aspecto temporal de la experiencia, como surgiendo de la continuidad. Desde otro ángulo, este constructo está asociado al concepto de inteligibilidad que alude a que el significado surge cuando se considera al otro social, al contexto institucional y cultural. Sobre este aspecto hacía relevancia el filósofo alemán W. Benjamin (1973) al advertir sobre la tendencia a alejarse del análisis histórico a nivel del intercambio social, señalando que cualquier reflexión acerca del pasado debe tomar en cuenta que este se soslaya fácilmente y es reemplazado por tendencias sociales dominantes que se imponen. Utilizando terminología teológica, el filósofo señala que lo que redime es el intento de no olvidar y el no olvidar significa, al mismo tiempo, poder avanzar en el presente. Este proceso no se realiza sino con otros. Es decir, el pasado requiere ser tomado en su dimensión histórica y cultural para que pueda haber un sentido y una coherencia.

Desde una perspectiva de la memoria histórica, no asignarle el peso que tiene al pasado nos haría caer en un riesgo solipsista, porque no existiría entendimiento entre las personas y pretenderíamos que el pasado es manejable en forma antojadiza por quien lo vive. Con este argumento, Benjamín rebate la noción de memoria intrapsíquica y unitaria como condición de veracidad y es categórico al restar protagonismo individual en pro de un proceso social.

La memoria, aquello que se recuerda, no aparece nunca desligada de la persona inserta en un contexto y siempre tiende a la continuidad de la experiencia de la persona en ese contexto. Entonces, dar sentido a un recuerdo o hacer sentido de lo pasado es histórico, dinámico, progresivo. 


\section{Hacia una reformulación del concepto de veracidad}

Si los recuerdos son considerados como construcciones en proceso, que se desarrollan en un contexto social y cultural, entonces el concepto de veracidad construido hasta ahora debería ser reconsiderado. Respecto del abuso sexual infantil hay un tema de carácter ético y legal que es necesario abordar. Las dificultadas para establecer la validez de los relatos de los niños acerca de experiencias de abuso sexual pueden tener serias consecuencias. Por una parte, ellos pueden no ser escuchados, debido a que sus recuerdos podrían ser juzgados como falsos. Por otra parte, personas inocentes pueden ser etiquetadas erróneamente como abusadores debido a la fabricación de recuerdos. En este contexto, la pregunta acerca de la memoria y de la validez de los recuerdos es ineludible. A la pregunta de cómo considerar la noción de veracidad al conceptualizar la memoria como fenómeno reconstructivo, cabe agregar nuevas preguntas. Entre otras, si se considera a la veracidad como un concepto que apunta a nociones morales de la conducta o epistémicas. Las razones éticas son las que nos llevan a plantear este tema como necesario al estudio y la investigación; sin embargo, no es la veracidad como tema moral el que atañe abordar, en cuanto a calificar a las personas como honestas o deshonestas. Tampoco es netamente en su significado epistémico, entendido como lograr obtener un conocimiento exacto, ya que ese objetivo respecto del pasado desde una perspectiva reconstructiva no es asequible.

Según Mead, el conocimiento no se identifica con la presencia de contenidos, sino que es un proceso de la conducta que organiza el campo de acción, así como dilata o inhibe respuestas. A partir de esto, la prueba del éxito del proceso de conocimiento, es decir, la prueba de veracidad en su sentido epistémico, se encuentra en el descubrimiento o construcción de objetos que pueden mediar nuestros conflictos, chequear nuestras actividades y permitir a la conducta proseguir. A través de estos conceptos, Mead introduce una noción de utilidad en la concepción de veracidad, donde 'mediar nuestros conflictos' es una acción con otros y la cultura, 'chequear nuestras actividades' es un proceso que retrotrae el pasado y 'proseguir la conducta' se refiere al movimiento de pre-adaptación al futuro inmediato, todos ellos como criterios de validez que guían la construcción del conocimiento. 
Se considera, entonces, la validez como una expresión del proceso reconstructivo de la memoria, de la temporalidad de la experiencia y que está asociada a conceptos de continuidad y de armar una totalidad. La validez apunta simultáneamente a dimensiones de temporalidad y estructura narrativa. En la temporalidad está la reconstrucción como proceso emergente en el presente, mientras que una narración prueba su coherencia en las interlocuciones de las distintas voces implicadas en el fenómeno que se está reconstruyendo, en el espacio social y cultural.

Se hace necesario una nueva formulación conceptual que integre las nociones de variabilidad y novedad de la experiencia presente, como asimismo de la naturaleza social y de mediación lingüística del proceso de construcción de significados. Un concepto que parece adecuado a ser aplicado en este contexto como noción de validez es hacer sentido. En lo cotidiano se entiende por hacer sentido a la facultad de las personas de juzgar razonablemente de las cosas; modo particular de entender una cosa o juicio que se hace de ella (Real Academia de la Lengua Española, 2001). A partir de esta definición, el sentido de un relato es una condición que está situada en el espacio interrelacional donde confluyen procesos personales y sociales que interactúan con los contextos históricos y culturales.

Un aspecto que está implicado en la noción de hacer sentido es la experiencia subjetiva de la persona quien, en calidad de protagonista de su experiencia, formula una narración acerca de situaciones vividas y que tienen un significado personal. Pero, además, este concepto de hacer sentido implica una necesaria relación con otros y sus discursos, en el presente. Aquí, la diferencia de perspectivas surge necesariamente, ya que un evento recordado, por su cualidad de imagen, permite la emergencia de múltiples versiones. Entonces, lo que cabe establecer son los límites de esas versiones, para considerar no una versión, sino un rango de versiones como válido. Esos límites, en el caso de los relatos de los niños, tienen que ver con los significados socialmente disponibles acerca de la experiencia que están dados desde el mundo adulto y el contexto sociocultural del niño que es validado por los adultos. El hacer sentido estaría dado a partir de las restricciones culturales.

Por otra parte, el sentido se construye en la tensión producida por las diferencias entre versiones sobre un fenómeno en el diálogo, esto es, en el espacio que permite la intersubjetividad (Marková, 2003; Valsiner, 2003; Coelho y Fegueiredo, 2003). Entendemos por intersubjetividad que 
las personas, para poder comunicarse, construyen colaborativamente una comprensión que comparten parcialmente con otros (Moghaddam, 2003). Hay un momento en que la tensión entre las diferencias se resuelve en favor de versiones compartidas por una comunidad local más amplia, o se rompe, fragmentándose en relatos dispersos carentes de relación entre ellos $\mathrm{y}$, por lo tanto, sin sentido. Lo que da sentido, entonces, es la relación que se establece entre diferentes relatos, lográndose una inteligibilidad que es construida en el proceso social, donde no caben versiones estáticas, únicas, particulares o repetibles.

Es útil, en este punto, recurrir a los conceptos desarrollados por Ricoeur (2001) en torno a lo que él denomina la pretensión de los relatos de decir la verdad. En su análisis de los actos narrativos son centrales las nociones de sentido y de inteligibilidad. El sentido, según Ricoeur, no apunta a eventos del pasado o a elementos subjetivos de la experiencia, sino que está referido al relato como elaboración lingüística, particularmente al acto narrativo, que coincide con la expresión de memoria más elaborada y propiamente humana, propuesta por Bartlett (1932). El acto narrativo tiene la capacidad de realizar una composición donde se reúnen elementos heterogéneos en una trama que expresa la temporalidad, llevando a que acontecimientos diversos adquieran inteligibilidad. En un relato se combinan la coherencia narrativa, sustentada sobre la temporalidad, y la conformidad con elementos extranarrativos. En el caso del abuso infantil, estos elementos serían documentos, pruebas legales, datos cronológicos, evidencia médica, fotografías, etc.

En términos de Ricoeur (2001), el relato del pasado, por ser inverificable, se caracteriza por una cierta suspensión de la referencia, lo que también es característico de la ficción. Esto no quiere decir que haya que renunciar a la referencia. Ricoeur habla de una referencia indirecta en el acto narrativo, desplazando la atención de una referencia a una realidad allá afuera, hacia el mensaje mismo, principalmente al aspecto descriptivo de los enunciados.

Así, Ricoeur pretende dar respuesta a la problemática planteada al conocimiento por el dualismo cartesiano, la división objetividad versus subjetividad, racionalismo versus hermenéutica, o lo que él denomina el problema de la referencia versus del sentido. Para Ricoeur, no es una cuestión ni dualista ni monista, sino que es un proceso dialéctico que va del sentido de un acto narrativo, de su cualidad inteligible dada por la trama y su capacidad para expresar el carácter temporal de la experiencia, a la 
referencia a una realidad determinada que es indirecta y que responde a la capacidad del relato de proyectarse hacia fuera en una representación del mundo. Ambos aspectos, el sentido y la referencia están comprendidos en un relato y, a partir de ellos, es necesario elaborar criterios que permitan la calificación de una narración como válida.

Desde este marco no interesa un contenido aislado de su contexto temporal y social, sino que es el proceso reconstructivo en sí el que requiere ser abordado en la forma más completa en que sea posible, entendiendo que esto no puede lograrse nunca completamente. Esto nos plantea una complejidad adicional. Conocer una "verdad" implica armar una totalidad, lo que demanda tolerar la variabilidad en los relatos como productos individuales, sociales y culturales de cada persona.

Aún no parece haberse desarrollado mayormente la investigación respecto a criterios de veracidad desde la perspectiva de memoria reconstructiva, lo cual implicaría un replanteamiento de las metodologías hacia aquellas que permitan el abordaje de procesos, apuntando a otro tipo de datos, no como datos fijos para ser calificados en relación a niveles de precisión, sino como expresiones de flujo temporal, desarrollos y estructuras narrativas y relatos construidos con otros. Queda planteado ese desafío.

\section{Conclusiones}

El presente artículo ha tomado como ejemplo de análisis el relato de niños y la expresión que genera mayores dificultades en la práctica para poder validarlos, esto es, las denuncias en torno a experiencias de abuso. Considerando la variable evolutiva, con frecuencia se atribuye a los niños características que son propias de los fenómenos psicológicos, en cuanto a su complejidad, variabilidad y puesta en contexto y que están presentes tanto en relatos de niños como adultos. Cuando se hace referencia a estas y otras situaciones de recuerdo, como de eventos no traumáticos o relatos de adultos, los conceptos aquí planteados son igualmente válidos a los cuales subyace el operar de la memoria.

Dicho lo anterior, cabe además plantearse si el relato del niño debiera ser el pilar que sustenta una acusación de abuso, dadas las obvias dificultades para obtenerlo de un niño que sufre experiencias traumáticas. Con esto se quiere hacer presente que se le exige a los niños que produzcan 
una narración de hechos pasados que satisfazga exigentes y necesarios estándares para ser aceptados por servicios sociales y ámbito judicial. Una consecuencia práctica sería que el relato de un abuso por parte de un niño fuera uno de los relatos, uno de los pilares, de modo que la narrativa del niño se cruzara con otras que comparten al menos parcialmente esa realidad, como hermanos, adultos protectores u otros. Se menciona este punto, porque el niño aparece considerado aislado en su individualidad en protocolos sobre veracidad y es el foco de atención de los expertos. Es más, se pretende aislarlo de la posible "contaminación" o influencia no deseada de otros según el criterio del profesional que evalúa. Sin embargo, acá se ha argumentado que la memoria es un proceso relacional, inserto en un particular contexto situacional, reexaminado constantemente. Es decir, en cada ocasión que un niño comenta, hace una asociación nueva, el relato se renueva también.

Los argumentos que se han desarrollado en el presente artículo han tenido la intención de llevar a una reflexión en torno a los fundamentos epistemológicos y filosóficos que están a la base de conceptos como memoria, tiempo, veracidad y validez de los relatos, cuestionando los supuestos que en la actualidad subyacen a su aplicación, los cuales han adoptado orientaciones cercanas a una filosofía dualista y una epistemología positivista. Este cuestionamiento plantea la exigencia de nuevas investigaciones orientadas a la elaboración de nuevos criterios que inspiren la práctica, en especial realizar evaluaciones periciales de casos en que los aspectos relevantes del contexto sean analizados. Si bien esta sugerencia puede complicar en torno a la complejidad de evaluación de los casos, es también cierto que en un gran número de ellos la información relevante está disponible en los equipos que trabajan con los niños abusados. Es más, acompañan a los casos en las presentaciones al ámbito legal. 


\section{Referencias bibliográficas}

Bartlett, F. (1932). Remembering. A study in experimental and social psychology. University Press.

Bauer, J. (1996). What do Infants Recall of their Lives? Memory for Specific Events by One to Two Year Olds. American Psychologist, 51(1), 29-41. https://doi.org/10.1037/0003-066x.51.1.29

Benjamin, W. (1973). Discursos Interrumpidos. Taurus.

Bergson, H. (1959). Materia y Memoria. En Obras escogidas (pp. 209-429). Aguilar.

Bursen, H. A. (1978). Dismantling the memory machine. Springer Netherlands. https://doi.org/10.1007/978-94-009-9885-8

Canton, J. y Cortés, M. (2000). Guía para la evaluación del abuso sexual infantil. Pirámide.

Ceci, S. J. y Bruck, M. (1993). Suggestibility of the child witness: A historical review and synthesis. Psychological Bulletin, 113(3), 403-439. https://doi.org/10.1037/0033-2909.113.3.403

Ceci, S. J. y Bruck, M. (2003). Jeopardy in the Courtroom. A Scientific Analysis of Children's Testimony. American Psychological Association.

Ceci, S. J. y Hembrook, H. (2002). Expert Witnesses in Chile Abuse Cases. American Psychological Association.

Coelho, N. y Figueiredo, L., (2003). Patterns of Intersubjectivity in the Constitution of Subjectivity: Dimensions of Otherness. Culture y Psychology, 9(3), 193-208. https://doi. org/10.1177/1354067X030093002

Faller, K.C. (1988). Decision-making in cases of intrafamilial child sexual abuse. American Journal of Orthopsychiatry, 58(1), 121-128. https://doi.org/10.1111/j.1939-0025.1988.tb01571.x

Echeburúa, E., Guerricaechevarría, C. y Vega-Osés, A. (1998). Evaluación de la validez del testimonio de víctimas de abuso sexual en la infancia. Revista Española de Psiquiatría Forense, Psicología Forense y Criminología, 5, 7-16.

Fiscalía Nacional del Ministerio Público de Chile, (2012, enero). Guía de Entrevista Investigativa con Niños, Niñas y Adolescentes Victimas 
de Delitos Sexuales. Unidad Especializada en Delitos Sexuales y Violentos.

Fivush, R. (1994). Young Children's Event Recall: Are Memories Constructed Through Discourse? En K. Pezdek y W. Barnes, (Eds.), The recovered memory/False memory Debate. Academic Press.

Gil, M.C., Schillagi, M.C., Squadrito, S. y Escalante Gómez, E. (2011). Evaluación y Análisis Fenomenológico del Relato en Pericias Realizadas por Abuso Sexual en Niños/as-Adolescentes. Liberabit. Revista Peruana de Psicología, 17(2), 157-171. https://www.redalyc. org/articulo.oa? $\mathrm{id}=68622584006$

Jones, D., (1992). Interviewing the sexually abused child. Investigation of suspected abuse. Gaskell, Royal College of psychiatrics.

Köhnken, G., Manzanero, A.L. y Scott, M.T. (2015). Análisis de la validez de las declaraciones: mitos y limitaciones. Anuario de Psicología Jurídica, 25(1), 13-19. https://doi.org/10.1016/j.apj.2015.01.004

Markova, I. (2003). Constitution of the self: Intersubjectivity and dialogicality. Culture and Psychology, 9(3), 249-259. https://doi. org/10.1177/1354067X030093006

Mead, G. H. (2002). The philosophy of the present. Prometheus Books.

Medina, J.A. Soriano, J.P. y Negre, M.C. (2014). Sistema de análisis de validez de las declaraciones (protocolo SVA) en un caso de abusos sexuales entre menores. Descripción de criterios y su aplicación. Gaceta Internacional de Ciencias Forenses (12), 69-79. https://dialnet. unirioja.es/servlet/articulo?codigo $=4779437$

Ministerio Público de Chile. (2019). Guía para la Evaluación Pericial de Testimonio en Víctimas de Delitos Sexuales.

Moghaddam, F. (2003). Interobjectivity and Culture. Culture y Psychology, 9(3), 221-232. https://doi.org/10.1177/1354067X030093004

Nelson, K. (1993). The Psychological and Social Origins of Autobiographical Memory. Psychological Science, 4(1), 7-14. http://www.jstor.org/ stable/40062495

Nelson, K. (2002). Language in cognitive development: The emergence of the mediated mind. Cambridge University Press. 
Ornstein, P.A., Ceci, S.J. y Loftus, E.F. (1998). Adult recollections of childhood abuse: Cognitive and developmental perspectives. Psychology, Public Policy, and Law, 4(4), 1025-1051. https://doi.org/10.1037/1076-8971.4.4.1025

Quiroga, M., Gil, C., Squadrito, S. y Campana, P. (2010). Evaluación pericial psicológica-psiquiátrica en casos de abuso sexual a niños/as y adolescentes. Revista de la asociación argentina de psicología. RAP, (48).

Real Academia de la Lengua Española. (2001). Diccionario de la Lengua Española.

Ricoeur, P. (2001). Del texto a la acción. Fondo de cultura económica.

Terr, L. (1996) True Memories of Childhood Trauma: Flaws Absence and returns. En K. Pezdek y W. Barney (Eds), The Recovered Memory/ False Memory Debate. Academic Press.

Tessler, M. y Nelson, K. (1994). Making Memories: The Influence of Joint Encoding on later Recall by Young Children. En K. Pezdek y W. Barnes (Eds.), The recovered memory/False memory debate. Academic Press.

Valsiner, J. (2000). Culture and Human Development. Sage Publications.

Valsiner, J. (2003). Editorial Introduction: Beyond Intersubjectivity. Culture \& Psychology, 9(3), 187-192. https://doi. org/10.1177/1354067X030093001 